\title{
Molecular characterization of resistance to Rifampicin in an emerging hospital-associated Methicillin-resistant Staphylococcus aureus clone ST228, Spain
}

Virginie Mick', M Angeles Domínguez ${ }^{1 *}$, Fe Tubau $^{1,2}$, Josefina Liñares ${ }^{1,2}$, Miquel Pujol ${ }^{3}$, Rogelio Martín ${ }^{1}$

\begin{abstract}
Background: Methicillin-resistant S. aureus (MRSA) has been endemic in Hospital Universitari de Bellvitge, Barcelona, since 1990. During the 1990-95 period the Iberian clone (ST-247; SCCmec-I) was dominant. Isolates of clonal complex 5 (ST-125; SCCmec-IV) gradually replaced the Iberian clone from 1996 to 2003. A new multiresistant MRSA phenotype showing rifampicin resistance emerged in 2004 and rapidly increased from 25\% in 2004 to 45\% in 2006. The aims of this study were i) the molecular characterisation of rifampicin resistant MRSA isolates, ii) the study of the rifampicin resistance expression by disk diffusion, microdilution and E-test, and iii) the analysis of the $r p o B$ gene mutations involved in rifampicin resistance.

Results: A sample of representative 108 rifampicin-resistant MRSA isolates belonged to a single PFGE genotype, ST-228, SCCmec type I and spa type t041. Of 108 isolates, 104 (96\%) had a low-level rifampicin resistance (MICs, 2 to $4 \mathrm{mg} / \mathrm{L}$ ) and 4 a high-level rifampicin resistance (MICs, $128-\geq 256 \mathrm{mg} / \mathrm{L})$. Disk diffusion and E-test methods failed to identify a low-level rifampicin resistance in 20 and 12 isolates, respectively. A low-level rifampicin resistance was associated with amino acid substitution 481His/Asn in the beta-subunit of RNA polymerase. Isolates with a high-level rifampicin resistance carried additional mutations in the rpoB gene.

Conclusions: The emergence of MRSA clone ST228-SCCmecl, related to the Southern Germany clone, involved a therapeutical challenge for treating serious MRSA infections. Decreased susceptibility to rifampicin in MRSA strains of ST228-SCCmecl was associated with one or two specific mutations in the rpoB gene. One fifth of isolates with low-level rifampicin-resistance were missed by the diffusion methods.
\end{abstract}

\section{Background}

Methicillin resistant Staphylococcus aureus (MRSA) is an important pathogen in Spanish hospitals. The percentage of patients infected or colonised by MRSA among patients with nosocomial $S$. aureus has been estimated between $20.2 \%$ and $30.5 \%$ in nation-wide multicenter studies $[1,2]$.

In the Hospital Universitari de Bellvitge MRSA has been endemic since 1990 . The majority of strains isolated during the 1990-95 period belonged to the multiresistant Iberian clone. By multilocus sequence typing

\footnotetext{
* Correspondence: adominguez@bellvitgehospital.cat

'Microbiology Department, Hospital Universitari de Bellvitge, University of Barcelona, IDIBELL, Feixa Llarga s/n 08907 Hospitalet de Llobregat, Barcelona, Spain
}

(c) 2010 Mick et al; licensee BioMed Central Ltd. This is an Open Access article distributed under the terms of the Creative Commons Attribution License (http://creativecommons.org/licenses/by/2.0), which permits unrestricted use, distribution, and reproduction in any medium, provided the original work is properly cited.
(MLST) the Iberian clone showed an allelic profile or sequence type (ST) 247, carrying the staphylococcal cassette chromosome mec (SCCmec) type I [3]. Isolates of the Iberian clone exhibited resistance against almost all antibiotics available for MRSA therapy including clindamycin, erythromycin, gentamicin, tobramycin, tetracycline, ciprofloxacin and rifampicin. From 1996 to 2003, the Iberian clone was gradually replaced by isolates of Clonal Complex 5 (ST125 and variants; SCCmec type IV) related to the Paediatric clone (ST5; SCCmec type IV) [4]. Unlike the Iberian clone, these strains showed only consistent resistance to tobramycin and ciprofloxacin combined with variable resistance to clindamycin and/or erythromycin. Similar trends have been observed in other hospitals in Spain and in other countries such 
as France, Germany, Belgium or Portugal, with involvement of different clonal lineages [5-10]. MRSA isolates resistant to clindamycin, erythromycin, gentamicin, tobramycin, and ciprofloxacin were detected in 2004 . These isolates showed reduced susceptibility to rifampicin (RIF-R), according to the Clinical and Laboratory Standards Institute (CLSI) criteria [11]. This new phenotype of multiresistance differed from that of the Iberian clone on the low level RIF- $R$ and on the tetracycline susceptibility. The frequency of the RIF-R MRSA isolates rapidly increased from 2004 to $2006: 25 \%(59 / 237)$ of all MRSA clinical isolates in 2004, 33\% (67/206) in 2005 , and $45 \%(116 / 256)$ in 2006 . The percentage of RIF-R MRSA decreased to $30 \%(111 / 378)$ in 2007 and $25 \%$ in 2008 (75/300).

Rifampicin cannot be used as a single agent to treat MRSA infections because of the rapid selection of resistant mutants $[12,13]$. However, combinations of rifampicin with other anti-staphylococcal agents such as quinolones [14] or fusidic acid [15] could prevent the emergence of rifampicin resistance during therapy [16]. Rifampicin interacts specifically with the RNA polymerase beta-subunit encoded by the gene $r p o B$ [12]. Rifampicin resistance in $S$. aureus, as in other bacteria, is associated with mutations in particular regions (cluster I and II) of the gene $\operatorname{rpoB}[13,17]$.

The objectives of the present study were: i) to characterise a collection of MRSA isolates expressing this new multiresistant pattern, and to determine whether they represented a novel genotype or they were the current representatives of a previously detected clone, ii) to determine the different levels of the rifampicin resistance by disk diffusion, microdilution and E-test, and iii) to analyse mutations in the rpoB gene related to rifampicin resistance.

\section{Methods}

\section{Hospital setting}

The Hospital Universitari de Bellvitge in Barcelona, Spain, is a nearly 900-bed tertiary care teaching centre. It is the reference hospital for a geographical area with a population of approximately 1 million inhabitants. The Hospital Universitari de Bellvitge in Barcelona provides medical and surgical care for adult patients with an average of 25,000 admissions per year. It has six intensive care units with a total of 60 beds and an active organ transplant program.

The control of MRSA in our institution is based on the active screening of patients at risk and contact isolation of infected or colonised patients. In spite of this policy, the average rate of total MRSA among $S$. aureus clinical isolates in our hospital was $24 \%$ for the 2004 2007 period (minimum 23\% in 2007 and maximum 26\% in 2006).
The present study has been approved by the Clinical Research Ethics Committee of the Hospital Universitari de Bellvitge.

\section{Bacterial strains}

Identification of $S$. aureus from clinical samples was performed using conventional tests: catalase, latex agglutination (Microgen Staph, Microgen Bioproducts, Camberley, England) and tube coagulase test (Staph-ase, bioMérieux, Marcy l'Étoile, France).

Two hundred and forty-two non-duplicate isolates resistant to clindamycin, erythromycin, gentamicin, tobramycin, ciprofloxacin and resistant to rifampicin (RIF-R) by the disk-diffusion or the microdilution method were recovered in the Microbiology Department of Hospital Universitari de Bellvitge from January 2004 to December 2006. These strains represented $34 \%$ of all MRSA isolated between 2004 and 2006, and were isolated from patients admitted to the different surgical, medical and intensive care units in the hospital. One hundred and eight isolates with rifampicin MIC $\geq 2 \mathrm{mg} /$ $\mathrm{L}$ were selected for the present study. The selection included the first isolates available each year $(33 / 59,29$ / 67 and 46/116 isolates from 2004, 2005 and 2006, respectively) from the different hospital wards affected. The origin of the strains was from blood cultures or catheter-related sites $(\mathrm{n}=38)$, wound swabs $(\mathrm{n}=28)$, respiratory samples $(n=24)$, exudates $(n=12)$, nasal swabs $(\mathrm{n}=4)$ and sterile fluids $(\mathrm{n}=2)$. Oral informed consent was given by all patients before taking the clinical specimen. The patient acquisition of MRSA infection or colonisation was prospectively assessed. Five strains with the same resistance pattern but fully susceptible to rifampicin (RIF-S) (MIC $0.012 \mathrm{mg} / \mathrm{L}$ ) were included in this study. This RIF-S pattern represented about $4 \%$ of all MRSA isolated between 2004 and 2006.

\section{Antimicrobial susceptibility testing}

Susceptibility testing of primary MRSA isolates is performed routinely by the disk-diffusion method on Mueller-Hinton 2 agar plates (MH2, bioMérieux) to the following antibiotics: penicillin (10 units), oxacillin (1 $\mu \mathrm{g})$, cefoxitin $(30 \mu \mathrm{g})$, erythromycin $(15 \mu \mathrm{g})$, clindamycin $(2 \mu \mathrm{g})$, gentamycin $(10 \mu \mathrm{g})$, tobramycin $(10 \mu \mathrm{g})$, rifampicin $(5 \mu \mathrm{g})$, tetracycline $(30 \mu \mathrm{g})$, trimethoprim-sulfamethoxazole $(1.25 / 23.75 \mu \mathrm{g})$, chloramphenicol $(30 \mu \mathrm{g})$, ciprofloxacin $(5 \mu \mathrm{g})$, vancomycin $(30 \mu \mathrm{g})$, teicoplanin $(30 \mu \mathrm{g})$, quinupristin/dalfopristin $(15 \mu \mathrm{g})$ and linezolid $(30 \mu \mathrm{g})$. Disks are supplied by BD BBL (Sensi-Disc; Becton, Dickinson and Company, Sparks, MD 21152 USA). MICs of rifampicin were determined in all strains selected for this particular study (108 RIF-R and 5 RIF-S MRSA strains) by microdilution (from 0.06 to $128 \mathrm{mg} / \mathrm{L}$ ), following the Clinical and Laboratory Standards Institute (CLSI) 
recommendations [11], and by E-test (AB biodisk, Solna, Sweden). Isolates were interpreted as susceptible or resistant, according to the CLSI criteria [11].

\section{Detection of rifampicin resistance-associated mutations}

An internal sequence of gene rpoB of 432 bp (nucleotides 1216 to 1648 ) was amplified by PCR. This region includes the rifampicin resistance-determining cluster I (nucleotides 1384-1464, amino acid number 462-488) and cluster II (nucleotides 1543-1590, amino acid number 515-530). The amplification was carried out in 5 RIF-S MRSA strains (rifampicin MICs, $0.012 \mathrm{mg} / \mathrm{L}$ ), and in a selection of 32 RIF-R strains showing different levels of rifampicin resistance: MICs $2 \mathrm{mg} / \mathrm{L}, 21$ strains; MICs $4 \mathrm{mg} / \mathrm{L}$, 7; MICs $128 \mathrm{mg} / \mathrm{L}, 2$; and MICs $\geq 256$ $\mathrm{mg} / \mathrm{L}, 2$. The oligonucleotide sequences used were rpoBfor (5'-GTC GTT TAC GTT CTG TAG GTG-3') and rpoBrev (5'-TCA ACT TTA CGA TAT GGT GTT TC3'). Amplification was carried out in a $50 \mu \mathrm{l}$ volume containing $30 \mathrm{pmol}$ of each primer, $200 \mu \mathrm{M}$ deoxynucleoside triphosphates (dATP, dCTP, dGTP and dTTP), $3 \mu \mathrm{l}$ of a template DNA sample and $1 \mathrm{U}$ of AmpliTaq Gold DNA polymerase (Applied Biosystems, Madrid, Spain). Thermal cycling reactions consisted of an initial denaturation $\left(9 \mathrm{~min} 30\right.$ at $94^{\circ} \mathrm{C}$ ) followed by 35 cycles of denaturation $\left(30 \mathrm{~s}\right.$ at $\left.94^{\circ} \mathrm{C}\right)$, annealing $\left(30 \mathrm{~s}\right.$ at $\left.62^{\circ} \mathrm{C}\right)$, and extension $\left(1 \mathrm{~min}\right.$ at $\left.72^{\circ} \mathrm{C}\right)$, with a final extension $\left(10 \mathrm{~min}\right.$ at $\left.72^{\circ} \mathrm{C}\right)$. The PCR product was purified (QIAquick PCR purification kit, Qiagen, Madrid, Spain) and analysed by DNA sequencing. Cycle sequencing reactions were made up in a final volume of $20 \mu \mathrm{l}$ with ABI BigDye Terminator v3.0 Ready Reaction Cycle Sequencing kit, following manufacturer's methodology (Applied Biosystems). The nucleotide sequences obtained were compared to the $r p o B$ wild type sequence from $S$. aureus subsp. aureus (GenBank accession number: X64172) using the clustalw software http://www.ebi.ac.uk/tools/ clustalw/index.html.

Rifampicin-susceptible strains used as controls were: ATCC29213 (rifampicin and methicillin susceptible S. aureus) and ATCC700698 (rifampicin susceptible MRSA). Two representatives of the Iberian clone were used as rifampicin-resistant MRSA controls: ATCCBAA44 $[18,19]$ and PER88 $[3,19]$.

\section{Determination of spontaneous mutation frequency for rifampicin resistance}

The determination of spontaneous mutation frequency for rifampicin resistance was aimed at identifying whether the presence of a first mutation conferring low level rifampicin resistance facilitated the acquisition of supplementary mutations responsible for increasing rifampicin MICs. The rifampicin mutation frequency was calculated in reference strain ATCC700698 (MIC
$0.006 \mathrm{mg} / \mathrm{L}$ ) and in two RIF-R MRSA strains carrying the low level resistance mutation His481/Asn (rifampicin MICs of 1.5 and $2 \mathrm{mg} / \mathrm{L}$, respectively). Bacterial strains were cultured in a shaking incubator at $37^{\circ} \mathrm{C}$ in Luria-Bertani (LB) broth (BD Diagnostics, Spain) until the exponential growth phase. Each strain was plated on the selective and non-selective LB agar plates and incubated at $37^{\circ} \mathrm{C}$. Rifampicin selecting concentrations were 2 and $20 \mathrm{mg} / \mathrm{L}$ for the reference strain, and $20 \mathrm{mg} / \mathrm{L}$ for the RIF-R MRSA strains. In these experimental conditions $\mathrm{OD}_{620}=0.125$ corresponded to $5 \times 10^{7} \mathrm{cfu} / \mathrm{ml}$. The equivalent to $10^{7}, 10^{8}$ and $10^{9} \mathrm{cfu}$ were spread on selective plates, and appropriated diluted samples were plated on non-selective plates. After $24 \mathrm{~h}$ to $36 \mathrm{~h}$, colonies that grew on selective and non-selective plates were counted and mutation frequencies were calculated. Three independent experiments were performed to ensure reproducibility.

\section{Molecular typing \\ Pulsed Field Gel Electrophoresis}

(PFGE) was performed after SmaI restriction of chromosomal DNA according to Chung et al. [20]. Pulses run from $5 \mathrm{~s}$ to $15 \mathrm{~s}$ for $10 \mathrm{~h}$ for block 1 , and from $15 \mathrm{~s}$ to $60 \mathrm{~s}$ for $13 \mathrm{~h}$ for block 2 [21]. Isolates with PFGE patterns differing in four or less restriction fragments were considered to be subtypes of a single genotype. Isolates with differences in more than four fragments were ascribed to distinct genotypes [22].

\section{SCCmec typing}

Molecular typing based on the amplification of the mobile region mec was performed according to previously described procedures [23,24]. Control strains for SCCmec typing were: ATCCBAA44 (SCCmec type I) $[18,19]$, ATCCBAA-41 (SCCmec type II) [19], ATCCBAA-39 (SCCmec type III) [19] and HGSA60 (SCCmec type IV-A) [24].

\section{Multilocus sequence typing}

(MLST). Analysis of the seven housekeeping gene sequences was performed according to previously described procedures http://saureus.mlst.net/[25].

\section{spa typing}

The polymorphic region of protein A was studied according to previously described procedures at http:// spa.ridom.de/[26]. The interest region was amplified with primers spa-1113f (5'-TAA AGA CGA TCC TTC GGT GAG C-3') and spa-1514r (5'-CAG CAG TAG TGC CGT TTG CTT-3’).

\section{Results}

Rifampicin resistance levels and associated rpoB mutations

The majority ( $\mathrm{n}=104,96 \%$ ) of the 108 RIF-R MRSA isolates, showed rifampicin MICs between 2 and $4 \mathrm{mg} /$ 
L. Two isolates had rifampicin MICs of $128 \mathrm{mg} / \mathrm{L}$ and the remaining two had MICs $\geq 256 \mathrm{mg} / \mathrm{L}$. Corresponding E-test and disk diffusion results are shown in table 1. On the basis of these results and following other authors' categorisation $[13,17,27]$ the strains were classified into categories of rifampicin susceptible (MICs, $\leq 0.5 \mathrm{mg} / \mathrm{L}$ ), low-level rifampicin resistance (MICs, 1 to $4 \mathrm{mg} / \mathrm{L}$ ), and high-level rifampicin resistance (MICs, $\geq$ $8 \mathrm{mg} / \mathrm{L}$ ). Interestingly, 20 strains with rifampicin MICs of $2 \mathrm{mg} / \mathrm{L}$ showed inhibition zones between 20 and $23 \mathrm{~mm}$, borderline to the susceptible CLSI breakpoint (inhibition zones $\geq 20 \mathrm{~mm}$ ). The five RIF-S MRSA isolates, with the same multi-resistance pattern, had rifampicin MICs of $0.012 \mathrm{mg} / \mathrm{L}$ and inhibition zones $>30 \mathrm{~mm}$.

The mutations in the rifampicin resistance-determining region of $r p o B$ gene were studied in 32 RIF-R and in 5 RIF-S MRSA strains. Results are shown in table 2. All 32 strains presented the mutational change $481 \mathrm{His} / \mathrm{Asn}$, determined by a mutation in cluster I of rpoB gene, conferring a low-level rifampicin resistance. The four isolates with $\mathrm{MIC} \geq 128 \mathrm{mg} / \mathrm{L}$ had an additional amino acid substitution: 468Gln/Lys $(\mathrm{n}=1)$, 477Ala/Thr $(\mathrm{n}=2)$ or 527Ile/Leu $(\mathrm{n}=1)$, associated with a high level rifampicin resistance. Mutational changes 468 and 477 were determined by mutations located in cluster I and substitution 527 was determined by a mutation located in cluster II. RIF-S MRSA isolates, had no mutations related to rifampicin resistance. All isolates, including RIF-S isolates, and 3 (ATCC29213, ATCCBAA44, and PER88) out of 4 control strains, presented a silent mutation in amino acid 498 with the substitution $\mathrm{Ala}(\mathrm{GC} \underline{\mathrm{G}})$ per $\mathrm{Ala}(\mathrm{GC} \underline{\mathbf{T}})$.

\section{Frequency of spontaneous mutation for rifampicin resistance}

The rifampicin mutation frequency was calculated in reference strain ATCC700698 (MIC, $0.006 \mathrm{mg} / \mathrm{L}$ ) and in two RIF-R MRSA strains carrying the low-level resistant amino acid substitution 481His/Asn (rifampicin MICs, 1.5 and $2 \mathrm{mg} / \mathrm{L}$, respectively). Rifampicin high level resistant mutants occurred with frequencies of around $10^{-7}$ to $10^{-8}$ in the RIF-R MRSA strains after selection by rifampicin concentration of $20 \mathrm{mg} / \mathrm{L}$. An identical mutational ratio was found in the control strain ATCC700698 at both selective concentrations ( 2 and $20 \mathrm{mg} / \mathrm{L}$ ).

\section{RIF-R MRSA genotypes by PFGE and epidemiology}

All 108 RIF-R MRSA isolates belonged to the same genotype by PFGE. This specific restriction pattern (B) was unique, distinct from both the PFGE patterns obtained for the multi-resistant RIF-S MRSA isolates (A) and

Table 1 MICs by microdilution and Etest and disk diffusion inhibition zones in 108 rifampicin resistant MRSA isolates

\begin{tabular}{ccccc}
\hline Microdilution MICs & No. of strains & E-test (range) MICs & \multicolumn{1}{c}{$\begin{array}{c}\text { Inhibition zones by disk diffusion } \\
\text { No. of strains }\end{array}$} \\
\cline { 3 - 5 } & & & $\leq 16 \mathrm{~mm}$ & $17-19 \mathrm{~mm}$ \\
\hline $2 \mathrm{mg} / \mathrm{L}$ & 97 & $0.75-2 \mathrm{mg} / \mathrm{L}$ & 75 & 62 \\
\hline $\mathrm{mg} / \mathrm{L}$ & 7 & $3-4 \mathrm{mg} / \mathrm{L}$ & 2 & - \\
$128 \mathrm{mg} / \mathrm{L}$ & 2 & $>32 \mathrm{mg} / \mathrm{L}$ & 2 & - \\
$\geq 256 \mathrm{mg} / \mathrm{L}$ & 2 & $>32 \mathrm{mg} / \mathrm{L}$ & 2 & - \\
\hline
\end{tabular}

Table 2 Level of rifampicin resistance and mutations found in the rpoB gene of MRSA isolates and control strains

\begin{tabular}{|c|c|c|c|c|}
\hline $\begin{array}{c}\text { Genotype } \\
\text { (ST/SCCmec/PFGE) }\end{array}$ & $\begin{array}{c}\text { Rifampicin MICs } \\
(\mathrm{mg} / \mathrm{L})\end{array}$ & Number of isolates & Nucleotide mutation & Amino acid substitution \\
\hline ST228/IV-A/A & 0.012 & 5 & None & \\
\hline ST228/I/B & $2-4$ & 28 & $\underline{C A T} \rightarrow \underline{A A T}$ & $481 \mathrm{His} \rightarrow$ Asn \\
\hline ST228/I/B & 128 & 2 & $\begin{array}{l}\mathrm{CAT} \rightarrow \mathrm{AAT} \\
\overline{\mathrm{G}} \mathrm{C} T \rightarrow \underline{\mathrm{A}} \mathrm{C} T\end{array}$ & $\begin{array}{l}\text { 481His } \rightarrow \text { Asn } \\
\text { 477Ala } \rightarrow \text { Thr }\end{array}$ \\
\hline $\mathrm{ST} 228 / \mathrm{I} / \mathrm{B}$ & $\geq 256$ & 1 & $\begin{array}{l}\mathrm{CA} T \rightarrow \text { AAT } \\
\overline{\bar{C}} \mathrm{~A} A \rightarrow \overline{\mathrm{A}} \mathrm{AA}\end{array}$ & $\begin{array}{l}481 \mathrm{His} \rightarrow \text { Asn } \\
468 \mathrm{G} \mathrm{ln} \rightarrow \text { Lys }\end{array}$ \\
\hline ST228///B & $\geq 256$ & 1 & $\begin{array}{l}\overline{\mathrm{CA} T} \rightarrow \mathrm{AAT} \\
\overline{\mathrm{A}} \mathrm{\underline {T }} \rightarrow \underline{\mathrm{C}} \mathrm{\underline {T }} T\end{array}$ & $\begin{array}{c}481 \mathrm{His} \rightarrow \text { Asn } \\
527 \mathrm{le} \rightarrow \text { Leu }\end{array}$ \\
\hline $\begin{array}{c}\text { ST247/I } \\
\text { PER88 } \\
\text { (Iberian clone) }\end{array}$ & $\geq 256$ & 1 & $\begin{array}{l}\text { CAT } \rightarrow \text { AAT } \\
\overline{\mathrm{T}} \mathrm{A} \rightarrow \overline{\mathrm{TTA}}\end{array}$ & $\begin{array}{l}481 \mathrm{His} \rightarrow \text { Asn } \\
529 \mathrm{Ser} \rightarrow \text { Leu }\end{array}$ \\
\hline $\begin{array}{c}\mathrm{ST} 247 / \mathrm{I} \\
\text { ATCCBAA44 } \\
\text { (Iberian clone) }\end{array}$ & 2 & 1 & $\underline{\mathrm{CAT}} \rightarrow \underline{\mathrm{AAT}}$ & $481 \mathrm{His} \rightarrow$ Asn \\
\hline
\end{tabular}


from representatives of the Iberian clone (figure 1). The RIF-R MRSA isolates were classified into eight subtypes (B-1 to B-8) with pattern B-1 being the most frequent (49\%; 53/108 strains), followed by subtype B-2 (34\%; 37/ 108). Subtype B-1 was dominant during 2004 representing $76 \%(25 / 33)$ of studied isolates, then decreased during 2005 (24\%; 7/29) and rose in 2006 to $48 \%(22 / 46)$. Subtype B-2 represented 52\% (15/29) in 2005, and $48 \%$ $(22 / 46)$ in 2006 . No correlation could be established between rifampicin resistance levels and PFGE subtypes. This RIF-R clone was not restricted to a specific hospital ward. Isolates were obtained from patients admitted to intensive care, medical and surgical units. Almost all patients included in this study $(101 / 108,93 \%)$ acquired the MRSA in our hospital. Seven patients acquired the RIF-R MRSA infection or colonisation in a prior admission to another hospital.

\section{SCCmec typing, MLST and spa typing}

SCCmec typing was carried out in the 32 strains where rpoB mutations were characterised. This selection included representatives of the eight PFGE B subtypes. Also RIF-S MRSA strains were analysed for SCCmec type. All 32 RIF-R MRSA strains carried a SCCmec type I. The 5 RIF-S of PFGE pattern A carried a SCCmec type IV-A. Interestingly, all strains belonged to a common MLST type: ST228, defined by alleles arcc 1, aroe 4, glpf 1, gmk 4, pta 12, tpi 24, and yqi 29 (table 3).

In parallel, a selection of 18 RIF-R MRSA strains and the 5 RIF-S MRSA were further genotyped by spa typing. All RIF-R strains belonged to spa-type t041. Among the RIF-S MRSA strains, three belonged to spa-type t2222 and two showed novel spa-types (r26-r30-r17-r13r17-r13-r17-r12-r17-r12 and r26-r30-r17-r20-r17-r12r17-r12-r17-r16).

\section{Discussion}

The multi-resistant nature of most MRSA clones found in hospitals represents a therapeutical challenge for treating serious MRSA infections. The burden that the Iberian clone posed in Spanish hospitals in the early $90 \mathrm{~s}[3,28]$, shifted to other clones susceptible to more

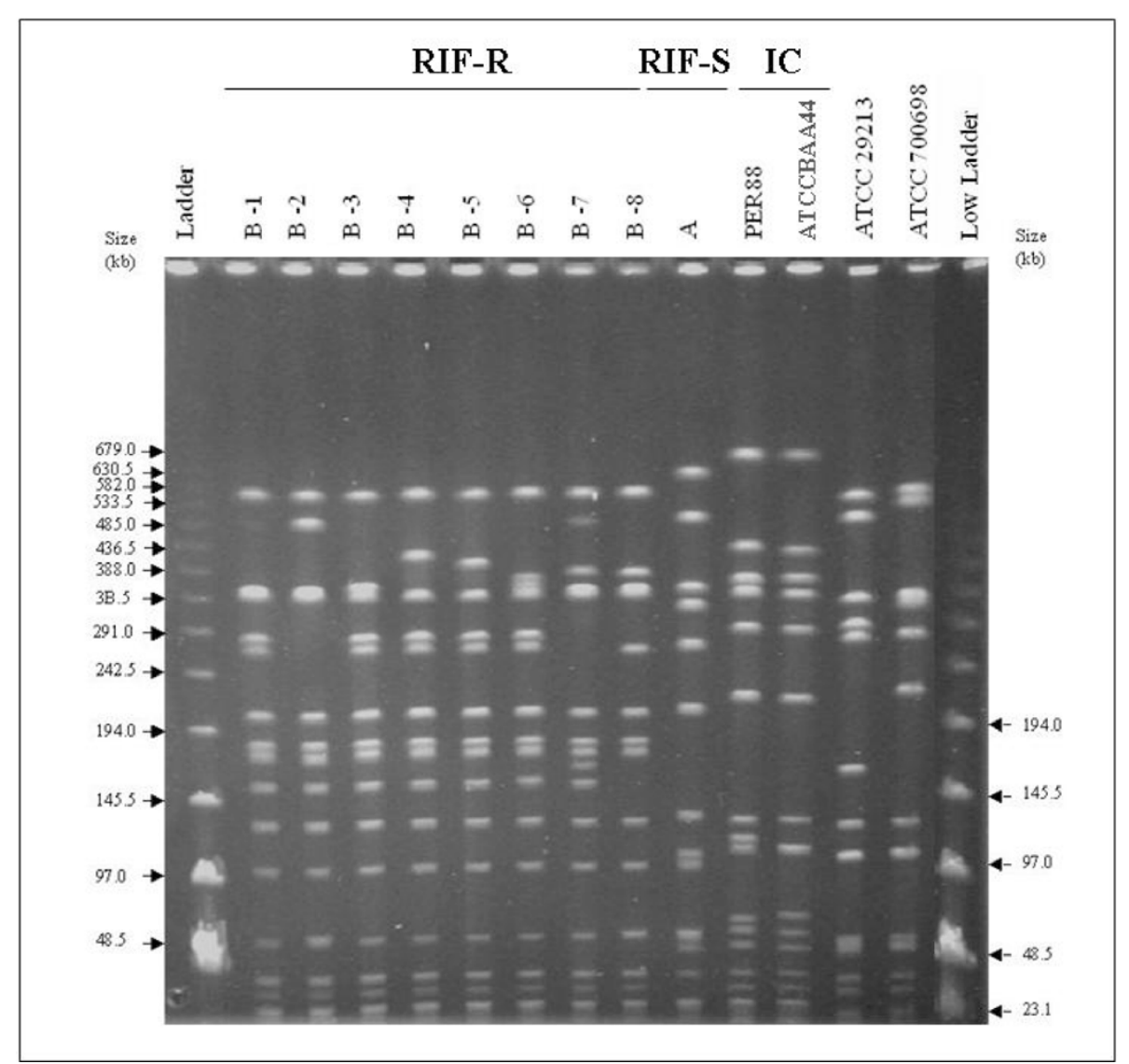

Figure 1 PFGE subtypes of MRSA strains with decreased susceptibility to rifampicin (RIF-R), "B-1" to "B-8". PFGE pattern "A" corresponds to a rifampicin susceptible MRSA isolate (RIF-S). PFGE patterns of controls are shown: Iberian clone (IC) representatives (PER88 and ATCCBAA44), ATCC2913 and ATCC70069. 
Table 3 Molecular features and resistance patterns of multi-resistant MRSA isolates resistant and susceptible to rifampicin

\begin{tabular}{ccccl}
\hline $\begin{array}{c}\text { MLST } \\
\text { (ST) }\end{array}$ & SCCmec type & PFGE & spa-type & Resistance pattern \\
\hline ST 228 & I & B & t041 & OXA, ERY, CLI, GEN, TOB, RIF, CIP \\
ST 228 & IVA & A & t2222 or novel & OXA, ERY, CLI, GEN, TOB, CIP \\
ST 247 & I & Iberian clone & t051 & OXA, ERY, CLI, GEN, TOB, RIF, CIP, TET \\
\hline
\end{tabular}

('OXA, oxacillin; ERY, erythromycin; CLI, clindamycin; GEN, gentamicin; TOB, tobramycin; CIP, ciprofloxacin; RIF, rifampicin)

antibiotics, which have been dominant in recent years $[8,29]$. In this paper, we described the emergence and spread of a MRSA clone resistant to clindamycin, erythromycin, gentamicin, tobramycin, ciprofloxacin and rifampicin which has reduced substantially the number of effective antibiotics for treatment of serious MRSA infections.

Rifampicin is an antibiotic of substantial interest in the rise of MRSA infections, but cannot be used as a single agent to treat such infections because rapid emergence of resistance can occur, even during therapy $[16,30,31]$. Although the role of rifampicin as adjunctive therapy is controversial [31], the combined therapy seems beneficial as long as the bacteria exhibit susceptibility to the antibiotics combined [30]. The distinctive phenotypic feature in the particular clone of ST-228 described here was the borderline resistance to rifampicin that could be missed by some methods of antimicrobial susceptibility testing (i.e. disk diffusion or E-test). Hence our interest in studying whether this low-level RIF-R was an adaptive phenomenon or to the contrary, known $r p o B$ mutations underlay such phenotype.

Almost all isolates belonging to this multi-resistant MRSA clone (104/108) showed a low-level rifampicin resistance (MICs, 1 to $4 \mathrm{mg} / \mathrm{L}$ ) and carried the amino acid substitution $481 \mathrm{His} / \mathrm{Asn}$ in the RNA polymerase. Only 4 isolates showed additional substitutions known to be involved in a high-level rifampicin resistance: two isolates (MICs, $128 \mathrm{mg} / \mathrm{L}$ ) carried mutational change 477 Ala/Thr, and one isolate (MIC, $\geq 256 \mathrm{mg} / \mathrm{L}$ ) $468 \mathrm{Gln} /$ Lys $[13,17,27,32]$. The fourth isolate (MIC, $\geq 256 \mathrm{mg} / \mathrm{L}$ ) showed substitution $527 \mathrm{Ile} / \mathrm{Leu}$, the only one which mutation was found in the rifampicin resistance-determining cluster II, described recently among Japanese MRSA isolates [32]. It is noteworthy that 20 isolates (19\%) of the RIF-R isolates, carrying rpoB mutation resulting in amino acid substitution in position 481 , were detected as rifampicin susceptible by the diskdiffusion test. However, the inhibition zones of these strains were between 20 and $23 \mathrm{~mm}$, closer to the susceptibility breakpoint established by CLSI (susceptibility $\geq 20 \mathrm{~mm}$ ) than inhibition zones among RIF-S MRSA isolates that were usually $\geq 30 \mathrm{~mm}$. Therefore, if screening for rifampicin resistance is made only by disk diffusion, special attention needs to be paid to strains borderline to the CLSI susceptibility breakpoint to avoid reporting false susceptibility results. MICs by E-test failed to detect rifampicin resistance following CLSI guidelines [11] in a group of 12 strains (MICs, 0.75-1 $\mathrm{mg} / \mathrm{L}$ ). These isolates showed MICs by microdilution of $2 \mathrm{mg} / \mathrm{L}$ and carried the $r p o B$ mutation responsible for amino acid substitution in position 481. Thus, and according to other authors, it would be advisable to apply $\leq 0.5$ and $\geq 8 \mathrm{mg} / \mathrm{L}$ as new breakpoints to classify rifampicin susceptibility or resistance in S. aureus clinical isolates [13,17].

High-level rifampicin resistance could be attributable to double mutations within $r p o B$, as previously described [27]. We did not find in this particular clone that the presence of a prior mutational change (481His/Asn) increased the frequency of acquisition of additional mutations responsible for a higher level of rifampicin resistance, when compared to a reference strain.

The multi-resistance pattern exhibited by the Iberian clone, dominant lineage in our hospital during the 90's, also included resistance to tetracycline. The new RIF-R MRSA isolates were resistant to clindamycin, erythromycin, gentamicin, tobramycin, ciprofloxacin and susceptible to tetracycline. However, molecular typing showed that the Iberian clone and the new RIF-R MRSA clone had different genetic backgrounds represented by ST-247 and ST-228, respectively, with only a single locus in common. Although both clones carried a SCCmec element type I, PFGE patterns and spa-types were clearly different.

All strains with the multi-resistant phenotype described in this work, showing resistance or decreased susceptibility to rifampicin, belonged to ST-228, carried a SCCmec element type I and were spa-type t041. This clone seems to be related to the Southern Germany clone (ST-228, SCCmec type I, spa-type t001 or spatype t041) reported in Germany in 1997-98 [21,33]. In the same period, strains of ST-228 and SCCmec type I were reported at several hospitals located in seven Italian cities [34], although these isolates also showed resistance to multiple antibiotics, rifampicin resistance was not stated. Recently, strains of ST-228 have spread epidemically in Finland in 2002-2004 and in Hungary in 
2003-2004 [35,36]. Also, ST-228 has been reported in other European countries: Belgium, Slovenia or Switzerland [37]. The first isolate ST-228, SCCmec type I was isolated in our hospital in September 2003, from a patient admitted to the ICU. However, it was not until March 2004 that this clone spread epidemically in our hospital and currently represents one third of all clinical MRSA isolates in our institution. Strains belonging to ST-228 have been reported in other hospitals in Spain since $1996[9,29,38]$. However, none of these reports (from Spain or other countries) analysed the decreased susceptibility to rifampicin among representative strains of ST-228. During the 2004-2007 period, we did not find significant changes in the rifampin consumption in our institution, which was on average $0.5 \mathrm{DDD} / 100$ patients-days for intravenous and 1.0 DDD/100 patientsdays for oral administration.

A set of 5 strains resistant to clindamycin, erythromycin, gentamicin, tobramycin, ciprofloxacin, but fully susceptible to rifampicin with MICs of $0.012 \mathrm{mg} / \mathrm{L}$ were included in this study. On average, this RIF-S pattern represented $4 \%$ of all MRSA isolated between 2004 and 2006, however this resistance phenotype can be traced back to 1999 in our hospital. The RIF-S isolates were classified as ST-228, the same as the RIF-R MRSA. Isolates of ST-228 (MLST, arcc 1, aroe 4, glpf 1, gmk 4, pta 12, tpi 24, and yqi 29) belong to the Clonal Complex 5, as well as isolates of ST-125 (MLST, arcc 1, aroe 4, glpf 1 , gmk 4, pta 12, tpi 1, and yqi 54) which was the dominant MRSA clone in Hospital Universitari de Bellvitge from 1996 to 2003. Consequently, an alternative hypothesis to explain the emergence of multiresistant clone ST-228, SCCmec type I would be the SCCmec type I transfer from ST-247 to the ST-125 background, with an intermediate stage where RIF-S isolates could be found belonging to ST-228.

\section{Conclusion}

Our study describes the hospitalary spread of an MRSA clone (ST-228, SCCmec-I, spa-t041), related to the Southern-Germany clone (ST-228, SCCmec type I, spatype t001 or spa-type t041) [21,33]. In this particular case, the studied strains were resistant to many more antibiotics than any previous MRSA clone spread in our institution, with the exception of the Iberian clone. In addition, the study of the rpoB mutations demonstrated that rifampin was not a suitable option for treatment of infections caused by this clone.

\section{Acknowledgements}

This work was supported by a grant from the Fondo de Investigaciones Sanitarias de la Seguridad Social (PI070944) and by Ministerio de Sanidad y Consumo, Instituto de Salud Carlos III - FEDER, Spanish Network for the Research in Infectious Diseases (REIPI RD06/0008). We thank Dr. Herminia de
Lencastre for providing us with some of the control strains included in this study.

\section{Author details}

'Microbiology Department, Hospital Universitari de Bellvitge, University of Barcelona, IDIBELL, Feixa Llarga s/n 08907 Hospitalet de Llobregat, Barcelona, Spain. ${ }^{2}$ CIBERES (CIBER de Enfermedades Respiratorias), ISCIII, Madrid, Spain.

${ }^{3}$ Infectious Diseases Department, Hospital Universitari de Bellvitge, University of Barcelona, IDIBELL, Barcelona, Spain.

\section{Authors' contributions}

$M D$ and $J L$ conceived the study and participated in its design. MD, FT, RM, $M P$ and $J L$ participated in field and clinical aspects of the study. VM and MD carried out the molecular genetic studies and sequence alignment. MD and VM wrote the manuscript which was co-ordinated by $\mathrm{JL}$ and critically reviewed by FT, RM and MP. All authors read and approved the final version of the manuscript.

Received: 2 August 2009 Accepted: 4 March 2010 Published: 4 March 2010

\section{References}

1. Rodríguez-Baño J, Millán AB, Domínguez MA, Almirante B, Cercenado E, Padilla B, Pujol M: Control of methicillin-resistant Staphylococcus aureus in Spanish hospitals. A survey from the MRSA 2003 GEIH/GEMARA/REIPI Project. Enferm Infecc Microbiol Clin 2006, 24:149-156.

2. Cuevas O, Cercenado E, Bouza E, Castellares C, Trincado P, Cabrera R, Vindel A: Molecular epidemiology of methicillin-resistant Staphylococcus aureus in Spain: a multicentre prevalence study (2002). Clin Microbiol Infect 2007, 13:250-56.

3. Domínguez MA, De Lencastre H, Linares J, Tomasz A: Spread and maintenance of a dominant methicillin-resistant Staphylococcus aureus clone during an outbreak of MRSA disease in a Spanish hospital. J Clin Microbiol 1994, 32:2081-87.

4. Sá-Leao R, Santos Sanches I, Dora Dias D, Peres I, Barros RM, De Lencastre H: Detection of an archaic clone of Staphylococcus aureus with low-level resistance to methicillin in a pediatric hospital in Portugal and in international samples: relics of a formerly widely disseminated strain? J Clin Microbiol 1999, 37:1913-20.

5. Amorim ML, Faria NA, Oliveira DC, Vasconcelos C, Cabeda JC, Mendes AC, Calado E, Castro AP, Ramos MH, Amorim JM, De Lencastre H: Changes in the clonal nature and antibiotic resistance profiles of methicillinresistant Staphylococcus aureus isolates associated with spread of the EMRSA-15 clone in a tertiary-care Portuguese Hospital. J Clin Microbiol 2007, 45:2881-88.

6. Denis O, Deplano A, De Ryck R, Nonhoff C, Struelens MJ: Emergence and spread of gentamicin susceptible strains of methicillin-resistant Staphylococcus aureus in Belgian hospitals. Microb Drug Resist 2003, 9:61-71.

7. Donnio PY, Preney L, Gautier-Lerestif AL, Avril JL, Lafforgue N: Changes in staphylococcal cassette chromosome type and antibiotic resistance profile in methicillin-resistant Staphylococcus aureus isolates from a French hospital over an 11 year period. J Antimicrob Chemother 2004, 53:808-13.

8. Montesinos I, Delgado T, Riverol D, Salido E, Miquel MA, Jimenez A, Sierra A: Changes in the epidemiology of methicillin-resistant S. aureus associated with the emergence of EMRSA-16 at a university hospital. J Hosp Infect 2006, 64:257-63.

9. Vindel A, Trincado P, Gomez E, Cabrera R, Boquete T, Sola C, Valdezate S, Saez-Nieto JA: Prevalence and evolution of methicillin-resistant Staphylococcus aureus in Spanish hospitals between 1996 and 2002. J Clin Microbiol 2006, 44:266-70

10. Witte W, Braulke C, Cuny C, Heuck D, Kresken M: Changing pattern of antibiotic resistance in methicillin-resistant Staphylococcus aureus from German hospitals. Infect Control Hosp Epidemiol 2001, 22:683-86.

11. Clinical and Laboratory Standards Institute: Performance standards for antimicrobial susceptibility testing. Sixteenth informational supplement M100-S17 CLSI, Wayne, PA, USA 2007.

12. Aboshkiwa M, Rowland G, Coleman G: Nucleotide sequence of the Staphylococcus aureus RNA polymerase rpoB gene and comparison of its predicted amino acid sequence with those of other bacteria. Biochem 1995, 1262:73-78. 
13. Aubry-Damon H, Soussy CJ, Courvalin P: Characterization of mutations in the $r p o B$ gene that confer rifampin resistance in Staphylococcus aureus. Antimicrob Agents Chemother 1998, 42:2590-94.

14. Zimmerli W, Widmet AF, Blatter M, Frei R, Ochsner PE: Role of rifampin for treatment of orthopedic implant-related staphylococcal infections. JAMA 1998, 279:1537-41.

15. Drancourt M, Stein A, Argenson JN, Roiron R, Groulier P, Raoult D: Oral treatment of Staphylococcus spp. infected orthopedic implants with fusidic acid or ofloxacin in combination with rifampicin. J Antimicrob Chemother 1997, 39:235-40.

16. Moellering RC: Current treatment options for community-acquired methicillin-resistant Staphylococcus aureus infection. Clin Infect Dis 2008, 46:1032-37.

17. Wichelhaus TA, Shäfer V, Brade V, Böddinghaus B: Molecular characterization of $r p o B$ mutations conferring cross-resistance to rifamycins on methicillin-resistant Staphylococcus aureus. Antimicrob Agents Chemother 1999, 43:2813-16.

18. Heym B, Le Moal M, Armand-Lefevre L, Nicolas-Chanoine MH: Multilocus sequence typing (MLST) shows that the 'Iberian' clone of methicillinresistant Staphylococcus aureus has spread to France and acquired reduced susceptibility to teicoplanin. J Antimicrob Chemother 2002, 50:323-29.

19. Oliveira DC, Tomasz A, De Lencastre H: The evolution of pandemic clones of methicillin resistant Staphylococcus aureus : identification of two ancestral genetic backgrounds and the associated mec elements. Microb Drug Resist 2001, 7:349-61.

20. Chung $M$, De Lencastre $H$, Matthews $P$, Tomasz A, Adamsson I, Aires de Sousa M, Cocuzza C, Corso A, Couto I, Dominguez MA, Gniadkowski M, Goering R, Gomes A, Hortal M, Kikuchi D, Marchese A, Mato R, Melter O, Oliveira D, Sa-Leao R, Song JH, Tassios P, Villari P: Molecular typing of Methicillin-resistant Staphylococcus aureus (MRSA) by pulsed field gel electrophoresis: comparison of results obtained in a multilaboratory effort using identical protocols and MRSA strains. Microb Drug Resist 2000 6:189-97.

21. Murchan S, Kaufmann ME, Deplano A, De Ryck R, Struelens M, Zinn CE, Fussing V, Salmenlinna S, Vuopio-Varkila J, El Solh N, Cuny C, Witte W, Tassios PT, Legakis N, Van Leeuwen W, Van Belkum A, Vindel A, Laconcha I, Garaizar J, Haeggman S, Olsson-Liljequist B, Ransjo U, Coombes G, Cookson B: Harmonization of pulsed-field gel electrophoresis protocols for epidemiological typing of strains of methicillin-resistant Staphylococcus aureus : a single approach developed by consensus in 10 European laboratories and its application for tracing the spread of related strains. J Clin Microbiol 2003, 41:1574-85.

22. Van Belkum A, Tassios PT, Dijkshoorn L, Haeggman S, Cookson B, Fry NK, Fussing V, Green J, Feil E, Gerner-Smidt P, Brisse S, Struelens M: Guidelines for the validation and application of typing methods for use in bacterial epidemiology. Clin Microbiol Infect 2007, 13:1-46.

23. Milheirico C, Oliveira DC, De Lencastre H: Update to the multiplex PCR strategy for assignment of mec element types in Staphylococcus aureus. Antimicrob Agents Chemother 2007, 51:3374-77.

24. Oliveira DC, De Lencastre H: Multiplex PCR strategy for rapid identification of structural types and variants of the mec element in methicillin-resistant Staphylococcus aureus. Antimicrob Agents Chemother 2002, 46:2155-61.

25. Enright MC, Day NP, Davies CE, Peacock SJ, Spratt BG: Multilocus sequence typing for characterization of methicillin-resistant and methicillinsusceptible clones of Staphylococcus aureus. J Clin Microbiol 2000, 38:1008-15.

26. Frénay HM, Bunschoten AE, Schouls LM, Van Leeuwen WJ, VandenbrouckeGrauls CM, Verhoef J, Mooi FR: Molecular typing of methicillin-resistant Staphylococcus aureus on the basis of protein A gene polymorphism. Eur J Clin Microbiol Infect Dis 1996, 15:60-64.

27. Wichelhaus TA, Böddinghaus B, Besier S, Shäfer V, Brade V, Ludwigh A Biological cost of rifampin resistance from the perspective of Staphylococcus aureus. Antimicrob Agents Chemother 2002, 46:3381-85.

28. Cuevas O, Cercenado E, Vindel A, Guinea J, Sanchez-Conde M, SanchezSomolinos M, Bouza E: Evolution of the antimicrobial resistance of Staphylococcus spp. in Spain: five nationwide prevalence studies, 1986 to 2002. Antimicrob Agents Chemother 2004, 48:4240-45.
29. Perez-Roth E, Lorenzo-Diaz F, Batista N, Moreno A, Mendez Alvarez S: Tracking methicillin-resistant $S$. aureus clones during a 5 -year period (1998 to 2002) in a Spanish hospital. J Clin Microbiol 2004, 42:4649-56.

30. Perlroth J, Kuo M, Tan J, Bayer AS, Miller LG: Adjunctive use of rifampin for the treatment of S. aureus infections. Arch Intern Med 2008, 168:805-19.

31. Schmitz FJ, Jones ME: Antibiotics for treatment of infections caused by MRSA and elimination of MRSA carriage. What are the choices? Int J Antimicrob Agents 1997, 9:1-19.

32. Sekiguchi J, Fujino T, Araake M, Toyota E, Kudo K, Saruta K, Yoshikura H, Kuratsuji T, Kirikae T: Emergence of rifampicin resistance in methicillinresistant Staphylococcus aureus in tuberculosis wards. J Infect Chemother 2006, 12:47-50

33. Wisplinghoff $H$, Ewertz B, Wisplinghoff $S$, Stefanik D, Plum G, PerdreauRemington $\mathrm{F}$, Seifert $\mathrm{H}$ : Molecular evolution of methicillin-resistant Staphylococcus aureus in the metropolitan area of Cologne, Germany, from 1984 to 1998. J Clin Microbiol 2005, 43:5445-51.

34. Mato R, Campanile F, Stefani S, Crisostomo MI, Santagati M, Sanches SI, De Lencastre $\mathrm{H}$ : Clonal types and multidrug resistance patterns of methicillin-resistant Staphylococcus aureus (MRSA) recovered in Italy during the 1990s. Microb Drug Resist 2004, 10:106-13.

35. Kerttula A, Lyytikäinen O, Kardén-Lilja M, Ibrahem S, Salmenlinna S, Virolainen A, Vuopio-Varkila J: Nationwide trends in molecular epidemiology of methicillin-resistant Staphylococcus aureus, Finland, 1997-2004. BMC Infectious Diseases 2007, 7:1-9.

36. Conceição $T$, Aires-de-Sousa $M$, Füzi $M$, Tóth $A$, Pászti J, Ungvári E, Van Leeuwen WB, Van Belkum A, Grundmann H, De Lencastre H: Replacement of methicillin-resistant Staphylococcus aureus clones in Hungary over time: a 10-year surveillance study. Clin Microbiol Infect 2007, 13:971-79.

37. Enright MC, Robinson DA, Randle G, Feil EJ, Grundmann H, Spratt BG: The evolutionary history of methicillin-resistant Staphylococcus aureus (MRSA). Proc Natl Acad Sci 2002, 99:7687-92.

38. Molina A, Del Campo R, Máiz L, Morosini Ml, Lamas A, Baquero F, Cantón R: High prevalence in cystic fibrosis patients of multiresistant hospitalacquired methicillin-resistant Staphylococcus aureus ST228-SCCmec I capable of biofilm formation. J Antimicrob Chemother 2008, 62:961-67.

doi:10.1186/1471-2180-10-68

Cite this article as: Mick et al:: Molecular characterization of resistance

to Rifampicin in an emerging hospital-associated Methicillin-resistant Staphylococcus aureus clone ST228, Spain. BMC Microbiology 2010 10:68.

\section{Submit your next manuscript to BioMed Central and take full advantage of:}

- Convenient online submission

- Thorough peer review

- No space constraints or color figure charges

- Immediate publication on acceptance

- Inclusion in PubMed, CAS, Scopus and Google Scholar

- Research which is freely available for redistribution

Submit your manuscript at www.biomedcentral.com/submit
Biomed Central 